\title{
EL PATRIMONIO DE HERNANDO ALONSO DE AMUSCO, CANÓNIGO DE LA CATEDRAL DE CORIA, A FINALES DE LA EDAD MEDIA ${ }^{1}$
}

\author{
THE PROPERTIES OF HERNANDO ALONSO DE AMUSCO, \\ CANON OF THE CORIA CATHEDRAL, \\ AT THE END OF THE MIDDLE AGES
}

\author{
FÁTIMA COTANO OLIVERA \\ Universidad de Extremadura
}

\begin{abstract}
Resumen: Los estudios sobre los cabildos catedralicios durante la Edad Media han sido esenciales para conocer la creación y posterior evolución de los obispados y diócesis de España. La conquista de la ciudad de Coria por Alfonso VII, en 1142, y la restauración de la diócesis fueron el paso definitivo para el origen y formación del cabildo. La documentación del archivo capitular muestra a la catedral como centro administrativo y símbolo de poder de la diócesis, especialmente durante la Baja Edad Media. Esta amplia información ha permitido conocer la estructura interna del cabildo - categorías y funciones-, la estratificación social y económica de cada uno de los miembros que lo componen, así como las relaciones del capítulo con otras instituciones eclesiásticas y civiles. Sin embargo, son escasas las ocasiones en las que la documentación aporta una información tan completa acerca de la vida, obra y costumbres de un miembro capitular.
\end{abstract}

Palabras clave: Historia eclesiástica; Baja Edad Media; Extremadura; Catedral; Cabildo; Canónigos; Patrimonio.

\begin{abstract}
Studies about the cathedral's chapters in the Middle Ages have been essential to know the creation and subsequent evolution of bishoprics and dioceses of Spain. The conquest of the city of Coria by Alfonso VII, in 1142, and the restoration of the diocese were the definitive step for the origin and formation of the chapter. The documentation of chapter archive shows the cathedral as the administrative center and symbol of power of the diocese, especially during the Late Middle Ages. This extensive information has revealed the internal structure of the chapter -categories and functions-, social and economic stratification of each of its members, as well as its relationships with other ecclesiastical and civil institutions. However, there are few occasions when the documentation provides very comprenhensive information about life, work and customs of a Chapter member.
\end{abstract}

Keywords: Ecclesiastic History; Late Middle Ages; Extremadura; Cathedral; Chapter; Canon; Heritage.

${ }^{1}$ Trabajo realizado dentro del Proyecto de Investigación Fuentes documentales para la Historia de Extremadura (Ref. 2PRO2A03), financiado por la Junta de Extremadura y el Fondo Social Europeo. El presente estudio se ha elaborado a partir de la ponencia presentada en las III Jornadas de Historia Medieval de Extremadura. En memoria del profesor Angel Barrios García (23-24 de noviembre de 2005), coordinado por el Dr. D. Julián Clemente Ramos. 


\section{SUMARIO}

1. Introducción. 2. Actividad capitular. 3. Patrimonio y actividad compradora. 3.1. La propiedad rústica. 3.2. La propiedad urbana. 3.3. Las caballerías. 3.4. Los esclavos. 4. Ajuar doméstico y objetos de uso diario. 5. La biblioteca del canónigo. 6. Conclusiones.

\section{INTRODUCCIÓN}

Uno de los aspectos más importantes de la vida de los canónigos de una catedral es conocer la evolución económica y social de sus miembros. Para la realización de este trabajo, hemos recurrido al estudio de uno de los personajes que cumple estos requisitos, el bachiller en Decretos Hernando Alonso de Amusco, canónigo en la Catedral de Coria (Cáceres). La documentación básica utilizada está relacionada con su participación como canónigo en los cabildos celebrados en la Catedral de Coria ${ }^{2}$, aunque será el inventario $^{3}$, redactado por el propio canónigo, el que nos aporte una información más detallada de sus actividades económicas. Otro documento importante es el referido a la fundación de la capellanía de Amusco ${ }^{4}$, así como una pesquisa dirigida a averiguar las circunstancias de su muerte ${ }^{5}$. Y en último lugar, las escrituras de compra-venta de numerosos bienes inmuebles.

La vida del canónigo Hernando Alonso de Amusco se caracterizó por una serie de circunstancias típicas de un miembro de segunda fila de la nobleza castellana del siglo XV. Su pertenencia a la casa de los Manrique de Lara evidencia una procedencia privilegiada y relacionada con su tío, don Ínigo Manrique, obispo de Coria (1457-1475). Las fuentes sobre los años anteriores a su llegada a Coria son escasas, aunque desde su llegada a la ciudad hasta su fallecimiento, la documentación generada es considerable. Según los datos recogidos en la pesquisa realizada en 1495 a ciertas personas que tuvieron una relación directa con el canónigo Amusco el día de su muerte, el 31 de marzo de 1493, día de Domingo de Ramos, las personas que se encontraban en la casa del canónigo fueron: Gonzalo Gómez Gil, escudero;

\footnotetext{
${ }^{2}$ Archivo Capitular de Coria (ACCo), Actas Capitulares, leg. 170, doc. 1. En José Luis MARTín MARTín, Documentación medieval de la Iglesia Catedrai de Coria, Salamanca, 1989, doc. 241: (1473-1500). Actas Capitulares de la Catedral de Coria. Son siete los libros que contiene los acuerdos de época medieval; a veces copian disposiciones aisladas y su información es incompleta.

${ }^{3}$ ACCo, Capellanías, leg. 54, doc. 14. En J. L. MARTín, Documentación medieval, ob. cit., doc. 229: (1469-1495) Cuaderno de cuentas del canónigo Fernando Alonso de Hamusco. Contiene un inventario de sus bienes a 1 de marzo de 1477; un resumen de los documentos que acreditan las compras que realizó en distintas fechas y diversas anotaciones marginales relacionadas con sus negocios.

${ }^{4}$ ACCo, Capellanías, leg. 54, doc. 17. Fundación de la capellanía de Hernando Alonso de Amusco (1489-marzo-25. Coria).

${ }^{5}$ ACCo, Posesiones y canonjías, leg. 30, doc. 6. (1495-septiembre-17. Coria). En J. L. MARTÍN MARTÍN, Documentación medieval, ob. cit., doc. 272: Pesquisa dirigida por el chantre de Coria y el canónigo Martín Gallos para averiguar el momento y las circunstancias del fallecimiento del canonigo Hernando Alonso de Hamusco, y determinar competencias sobre la canonjía vacante. El autor recoge el documento como ACCo, leg. 30 doc. 3.
} 
Mari López, criada; Fernando Marín de Montemayor, canónigo de Coria; Fernando García de Mendaña, relojero, además de otras personas. Estos testigos afirman, en su mayoría, que el citado canónigo tenía una edad comprendida entre los 65 y 70 años, era alto enjuto, de tez cetrina y pelo cano $^{6}$. Si atendemos a los datos aportados por las fuentes, la presencia del bachiller Amusco en la diócesis de Coria se prolongó durante más de 30 años.

Las actividades llevadas a cabo por el bachiller Hernando Alonso de Amusco se mueven en dos ámbitos fundamentales de la vida de cualquier miembro del cabildo. Por un lado, su actividad eclesiástica, tanto en los trabajos propios de cualquier eclesiástico: asistencia al coro, eucaristías o cumplimiento de la residencia; y en el apartado de la administración de la catedral, ocupándose, en ciertos momentos, de la administración episcopal y capitular. Por otro lado, en el ámbito privado, ser el administrador de sus bienes (muebles, raíces, dinero), para acrecentar su hacienda. Esta actividad económica privada se refleja en las escrituras de compra de inmuebles urbanos y rústicos, especialmente, de dehesas.

\section{ACTIVIDAD CAPITULAR}

En la Baja Edad Media, la relación entre la nobleza y la Iglesia se asentaba en los lazos de unión entre ambos sectores sociales a través de la posesión de cargos eclesiásticos por parte de los llamados "segundones" de la nobleza ${ }^{7}$. Éste podría ser el caso del canónigo Amusco, pues, como citamos anteriormente, su tío don Íñigo Manrique de Lara fue obispo de Coria. Asî pues, la elección de Hernando Alonso de Amusco como canónigo no fue casual, sino que vino acompañada por la relación familiar existente entre el obispo y el bachiller, ambos descendientes de un ilustre linaje castellano. A pesar de esta conexión familiar no hay que descartar la preparación académica del propio canónigo ya que fue bachiller en Decretos y ocupó el cargo de oficial y vicario general del obispado. Este último puesto está relacionado íntimamente con la confianza depositada por el obispo en un miembro de su familia en unos momentos turbulentos, especialmente en el territorio de Coria durante la guerra civil castellana.

El bachiller en Decretos Hernando Alonso de Amusco, probablemente, entró a formar parte de la vida eclesiástica de la diócesis de Coria antes de 1463, cuando don Iñigo Manrique de Lara ${ }^{8}$ le concede la canonjía que estaba

${ }^{6}$ Ibídem.

${ }^{7}$ Ramón SÁNCHEZ GONZÁLEZ, Iglesia y sociedad en la Castilla Moderna. El Cabildo catedralicio de la Sede Primada (siglo XVII), Toledo, 2000, p. 31.

${ }^{8}$ Miguel Ángel ORTí Y BELMONTE, Episcopologio Cauriense, Cáceres, 1959, pp. 65-68. En el Episcopologio se recogen los acontecimientos mâs importantes del episcopado de don Inigo Manrique de Lara, descendiente de don Pedro Manrique, VIII señor de Amusco, entre otros títulos Y Adelantado Mayor de Cạstilla, y de doña Leonor de Castilla. Los hermanos son don Diego Manrique, conde de Treviño, don Juan Manrique, conde de Castañeda, don Rodrigo Manrique, conde de Paredes, y don Gabriel Manrique, conde de Osorno. Como podemos observar, el linaje de los Manrique de Lara era, pues, uno de los más importantes del Reino de 
vacante por la muerte de Juan de Medina. El documento recoge las directrices de la elección por "la sufiçiençia, liçepnura e abilidad de vos el honrrado Ferrand Alfonso de Hamusco, bachiller en Decretos, nuestro ofiçial e vicario general que agora soys en la nuestra Iglesia e Obispado de Coria. E por vos faser bien e merçed, damos vos e asignamos vos canoniçem et ynperpetum para en todos vuestros días la calongía e prebenda de la dicha nuestra Iglesia de Coria que vacó e segund que de presente está vaca por fyn e muerte de Juan de Medina (...) vos fazemos colaçión e canónica ynistituçión de la dicha calongía e prebenda por ynposiçión de nuestro anillo que personalmente a Ferrand García de Bezerril, nuestro capellán, en vuestro nonbre e para vos en

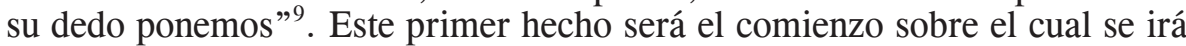
construyendo la economía del canónigo Amusco, gracias a la prebenda y las distribuciones asignadas a la canonjía ${ }^{10}$.

La primera aparición del bachiller fue como "provisor"11, es decir, juez diocesano, nombrado por el obispo con potestad ordinaria para entender causas eclesiásticas, y su posterior nombramiento como canónigo de la Catedral de Coria. Éstos no fueron, ni mucho menos, los únicos cargos desempeñados. En el registro de las actas capitulares el bachiller Hernando Alonso de Amusco aparece, en ocasiones, como un simple "testigo" 12 de los hechos anotados. Aunque, su importancia dentro del cabildo se verá recompensada con el cargo temporal de "presydente" ${ }^{13}$ del cabildo, quien "proponía los temas del orden del día, moderaba las discusiones, decidía el momento de votar y, al final, resumía lo acordado" ${ }^{14}$, que es precisamente lo que se registra en las actas capitulares. Aparece también como sustituto del deán en calidad de "viçedeán"15, o "lugarteniente de deán"16; igualmente, es citado como "lugarteniente de viçedeán" 17 .

Este personaje aparece en las actas capitulares como un miembro reconocido por el colectivo catedralicio. Desempeñó distintos puestos u oficios relacionados con la administración del patrimonio ${ }^{18}$. En 1473, el bachiller

Castilla a finales del siglo XV.

${ }^{9} \mathrm{ACC}$, Posesiones y canonjías, leg, 30, doc. 2 , ff. 1 v-2 r. 1463-septiembre-27. Toledo. Regesta en J. L. MARTín, Documentación medieval, ob. cit.. doc. 221: 1463, septiembre, 27. Don Iñigo Manrique, obispo de Coria, concede a Fernando de Hamusco, bachiller en Decretos y vicario general en el obispado, la canonjía y prebenda vacante por el fallecimiento de Juan de Medina.

${ }^{10} \mathrm{ACC}$, Actas Capitulares, leg. 170, doc. 3. En estas actas se recoge la cuantía que reciben los herederos de Hernando Alonso de Amusco, en 1494, los $12.000 \mathrm{mrs}$ que le correspondían de la mesa capitular. Era costumbre que los herederos recibiesen las rentas del año siguiente a la muerte de los eclesiásticos.

${ }^{11} \mathrm{ACC}$, Actas Capitulares, leg. 170, doc. 2, f.24 r.

${ }^{12} \mathrm{ACC}$, Actas Capitulares, leg. 170, doc. 1, f.17 r.

${ }^{13} \mathrm{ACC}$, Actas Capitulares, leg. 170, doc. 2, f.3 v.

${ }^{14}$ Antonio CABEZA, La vida en una Catedral del Antiguo Régimen, Palencia, 1997, p. 54.

${ }^{15} \mathrm{ACC}$, Actas Capitulares, leg. 170, doc. 2, f.3 v.

${ }^{16} \mathrm{ACC}$, Actas Capitulares, leg. 170, doc. 2, f.4 v.

${ }^{17} \mathrm{ACC}$, Actas Capitulares, leg. 170, doc. 2, f.3 r.

${ }^{18}$ Tomás VILLACORTA RODRíGUEZ El El Cabildo Catedral de León. Estudio histórico-jurídico: siglos XII-XIX, León, 1974, pp. 376-378. 
Hernando Alonso de Amusco fue mayordomo del obispo, por tanto, encargado de "resçebyr e recabdar en el año de setenta e uno que se ovieren a reçebyr e recabdar en el año de setenta e dos asy de pan e vino e menudos e carneros e diesmos de yerbas e dehesas, prados e pastos cathedráticos e deninasgos e rentas de nuestros cilleros de Santa Crus y Villanueva"19. También llevó cuentas del cabildo. El 29 de diciembre de 1473 el deán y cabildo de la catedral "fesieron su resçebtor al honrrado bachiller Fernand Alonso de Hamusco, canónigo, presente deste año presente e le dieron poder bastante para demandar, resçebir e aver e cobrar todas las rentas a ellos pertenesçientes e a su mesa capitular del año pasado de setenta y dos que se cojen e recabdan en este de setenta e tres e dar cartas de pago e ynjuisar" ${ }^{20}$. El trabajo de mayordomo del obispo y receptor de las rentas del cabildo denota la importancia de un miembro del cabildo en los asuntos económicos, si bien la economía era uno de los puntos más sensibles de la Iglesia de Coria como eran las percepciones de rentas, diezmos y otros derechos, especialmente en los distintos territorios de la Orden de Alcántara.

Encontramos al bachiller Amusco como "contador" ${ }^{21}$, es decir, el encargado de la entrada y salida de caudales, haciendo el cargo a las personas que los perciben, y recibiéndoles en data lo que pagan, con los recados de justificación correspondientes. También como "reçebtor de los señores dean e cabildo" 22 , es decir, como escribano comisionado por un tribunal para hacer cobranzas, recibir pruebas u otros actos judiciales. También aparece como "mayordomo" 23 , es decir, que el bachiller Hernando Alonso de Amusco era la persona que durante un año administraba y repartía las rentas de la mesa capitular ${ }^{24}$, dependiendo exclusivamente del deán y cabildo ${ }^{25}$. Dichas rentas estaban compuestas por aquellas provenientes de las rentas del pan, vino y dinero procedente de los diezmos, y también de los bienes raíces del cabildo (posesiones, heredades y casas).

El 27 de noviembre de 1481 es elegido nuevamente mayordomo y receptor por el deán y cabildo, aunque " no lo podía faser por ser ynpidido de hedad (...)"26. El reconocimiento del deán y cabildo se hace patente, pues, tal y como se observa, el bachiller ya no estaría en disposición de ejercer estos oficios por cuestiones de edad, pero, de nuevo, la importancia de sus conocimientos económicos y jurídicos hacen que la presencia del bachiller se haga patente a pesar de contradecir una norma de acceso a un oficio. Sin

\footnotetext{
${ }^{19} \mathrm{ACC}$, Datos biográficos de Obispos, leg. 21, doc. 8. (1473-febrero-27. Calabazanos).

${ }^{20} \mathrm{ACC}$, Actas Capitulares, leg. 170, doc. 1, f.1 r.

${ }^{21} \mathrm{ACC}$, Actas Capitulares, leg. 170, doc. 2, f.4 v.

${ }^{22}$ ACCo, Actas Capitulares, leg. 170, doc. 2, f.18 v.

${ }^{23}$ ACCo, Actas Capitulares, leg. 170, doc. 2, f.22 v.

${ }^{24}$ Teófilo PORTILLO CAPILLA, "Vida administrativa en las catedrales en los siglos XII al XVI", en Memoria Ecclesiae IV, (1993), Oviedo, p. 95.

${ }^{25}$ José Luis MARTín MARTín, Las constituciones de la Iglesia de Coria de 1315, "Miscelánea Cacereña", Primera serie (1980), p. 69.

${ }^{26}$ ACCo, Actas Capitulares, leg. 170, doc. 2, f.13 v.
} 
duda, sus conocimientos de gestión económica los podemos corroborar con su exquisita descripción de sus apuntes en el inventario de bienes ${ }^{27}$ : cuentas sobre la compra de cera, de propiedades rústicas y urbanas, de esclavos y caballerías, y el inventario de los bienes que están en sus casas de Coria y Acebo: muebles, ropa, armas, libros, escrituras y material de escritorio.

\section{PATRIMONIO Y ACTIVIDAD COMPRADORA}

Hernando Alonso de Amusco, tal y como hemos expuesto anteriormente, perteneció a la familia de los Manrique de Lara, ya que aparece el blasón de la familia con el caldero y las sierpes, tanto en la reja como en el arco de la capilla que fundó el dicho bachiller en $1489^{28}$. Además, en la sepultura gótica, situada en el lateral izquierdo de la capilla contiene dos blasones en la tapa inclinada de la misma y, otro de mayor tamaño, en el lateral ${ }^{29}$. Su adscripción a una de las familias más importante del reino de Castilla posibilitó un escalafón socioeconómico inmejorable para engrandecer su propia hacienda. Tanto es así, que el escribano Diego González de Plasencia comenta que el bachiller "començó a hasendar e conprar e tener hazienda e renta de yerva" 30 . El resultado de este proceso de formación de un patrimonio se corrobora en una afirmación del canónigo, quien dice que "lo espiritual no se puede sostener syn lo tenporal"31. Un lema que, quizás, sea el eje sobre el cual descansa todo el afán inversionista de nuestro personaje y cuyo fin es la institución de una capilla de Santa María de la Encarnación, donde más tarde descansarían sus restos mortales.

La inversión llevada a cabo por el dicho canónigo es muy superior a la realizada por otros miembros del cabildo. Su pertenencia a uno de los linajes más importantes de Castilla fue seguramente un factor que facilitó sus numerosas adquisiciones patrimoniales. Observamos que la compra de propiedades se efectuó en la época en que el bachiller desempeñó varios cargos administrativos, sobre todo, hacia finales de la década de los setenta, cuando realizó las inversiones más importantes en bienes raíces. Las cantidades invertidas son las siguientes:

\footnotetext{
${ }^{27} \mathrm{ACC}$, Capellanías, leg. 54, docs. 11 y 14.

${ }^{28}$ ACCo, Capellanías, leg. 54, doc.17. Fundación de la capellanía de Hernando Alonso de Amusco (1489-marzo-25. Coria)

${ }^{29}$ Florencio-Javier García Mogollón, La catedral de Coria. Arcón de Historia y Fe, León, 1999, pp. 98-101.

${ }^{30}$ ACCo, Capellanías, leg. 54, doc. 17, f.1 r. En J. L. Martín Martín, Documentación medieval, ob. cit., doc. 246: (1489-marzo-25. Coria). Fernando Alonso de Hamusco, canónigo, expone a sus compañeros reunidos en cabildo su decisión de dotar dos capellanías y a seis mozos de coro en la capilla de Santa María de la Encarnación, que había mandado construir en la catedral de Coria. Para ello dona la parte que posee en la dehesa de Valvellido, su parte en la dehesa de Encín de los Álamos y dos pares de casas en Coria. A los mozos de coro dejó la dehesa de los Prados, cerca de Torrejoncillo.

${ }^{31}$ ACCo, Capellanías, leg. 54, doc.17, f.2 r. Fundación de la capellanía de Hernando Alonso de Amusco (1489-marzo-25. Coria).
} 
Cuadro I: Inversiones

\begin{tabular}{|l|l|c|}
\hline TIPOLOGÍA & MARAVEDÍES* & PORCENTAJE \\
\hline Propiedad rústica** & $497.469,5$ & $74,46 \%$ \\
\hline Propiedad urbana & 119,620 & $17,90 \%$ \\
\hline Caballerías & 28.275 & $4,23 \%$ \\
\hline Esclavos & 22.730 & $3,40 \%$ \\
\hline TOTAL & $\mathbf{6 6 8 . 0 9 4 , 5}$ & \\
\hline
\end{tabular}

* Están incluidas las alcabalas pagadas.

** La propiedad rústica está calculada sin contabilizar el precio de los 50 mrs de la majada en la dehesa de Malpartida.

Como podemos observar en el Cuadro I la inversión más importante realizada por el canónigo Amusco fue la referida a la propiedad rústica, seguida de la urbana, y en tercer y cuarto lugar y con menor gasto, las correspondientes a las caballerías y esclavos.

\subsection{La propiedad rústica}

La compra de propiedades rústicas (dehesas, tierras y viñas) ocupa el $74,46 \%$ de la inversión total llevada a cabo por el bachiller, con un total de 497.469,5 mrs. Dicha cantidad ocupó gran parte del esfuerzo económico realizado por Hernando Alonso de Amusco a lo largo de su presencia en la catedral. La inversión se dirigió, en gran medida, a la adquisición de dehesas $^{32}$. La economía bajomedieval extremeña se caracterizó por ser una economía agroganadera desarrollada esencialmente en las dehesas, espacios dedicados al cultivo de cereales y a la cría de ganado. La posesión de estas dehesas era muy importante para la hacienda del canónigo Amusco pues eran arrendadas mediante contratos vitalicios o censos a los concejos o a particulares con cierto nivel económico ${ }^{33}$. No en vano, en 1489 , cuando realiza la institución de la capellanía, el canónigo Amusco expresa los bienes que serán adscritos a ella. Dicho año, tiene alquilada la dehesa de Valvellido por un valor de 14.725 mrs y un puerco, mientras que el concejo del Pedroso tiene

\footnotetext{
${ }^{32} \mathrm{M}^{\mathrm{a}}$ Dolores GARCía OLIVA, Orígenes y expansión de la dehesa en el término de Cáceres, "Studia Histórica", IV, 2, (1986), p. 96; M" del Carmen MARTÍN MARTín, "La Explotación de las propiedades rurales del cabildo catedralicio de Plasencia durante el siglo XV, en II Jornadas de Historia Medieval de Extremadura, Mérida, 2005, p.161.

${ }^{33} \mathrm{ACC}$, Actas Capitulares, leg. 170, doc. 1, f.9 r: "por razón del agostadero de la su dehesa de Malpartida que compró del mayordomo Ferrand Alonso de Hamusco". ACCo, Actas Capitulares, leg. 170 , doc. 1, f.14 r: "por razón „del agostadero del ochavo de Tel Dias que compró del'bachiller Ferrand Alonso de Hamusco".
} 
arrendada la dehesa del Encín de los Álamos por $12.208 \mathrm{mrs}$, dos cornados, 31 fanegas y 8 celemines tanto de trigo como de cebada y "de las gallinas dose pares menos un quarto de gallina”. Las rentas anuales de ambas dehesas serán para los dos capellanes. Mientras que la dehesa de los Prados fue arrendada por $4.000 \mathrm{mrs}$, libres alcabala y diezmo, y dos carneros ${ }^{34}$, y su renta iba a parar a los seis mozos de coro.

La importancia de la edificación de la Capilla de Nuestra Señora de la Encarnación puso de manifiesto una carencia evidente dentro de la Catedral de Coria por el "defecto del serviçio del coro en los ofiçios divinos a cabsa del poco número de los capellanes de la dicha yglesia y porque aún muchas vezes algunos dellos faltavan de la dicha yglesia e coro o por enfermedad o por otras cosas o negoçio (...) deseando de aumentar el culto divino e porque el tal defecto en algo más se supliese y los dichos señores (del cabildo) fuesen ayudados" 35 en el coro. De esta manera, el canónigo une la necesidad acuciante de nuevos capellanes y mozos de coro y la puesta en marcha de su capilla, donde reposen sus restos mortales y se rece por él y su familia.

Las condiciones sobre las que se instituye esta capellanía son las siguientes:

-Servicio de los dos capellanes en la iglesia y en el coro durante todas las horas, tanto diurnas como nocturnas, salvo la prima y el aniversario.

-Todos los días del año, al alba, digan una misa cantada de Nuestra Señora, también por las ánimas del canónigo y su familia y misa por la Paz o el Espíritu Santo, exceptuando los domingos, fiestas principales y de guardar, que se hará rezada. La misa la dirá un capellán, mientras que el otro, junto con los 6 mozos de coro, la ofician. Estos mozos de coro deben tener conocimiento de canto.

-Alternancia de los capellanes a la hora de decir misa. El primero dirá 4 misas, mientras que el otro 3. A la semana venidera, se realizará al revés.

-Multa por ausentarse de la misa: un real de plata. la capellanía.

-La percepción de las rentas de los bienes asignados en la escritura de

-Los patronos de la capellanía: el deán y cabildo, sin intromisión del obispo en el nombramiento de capellanes y mozos de coro. En caso contrario, se venderán los bienes y del dinero resultante, se destinaría a la redención de cautivos cristianos.

Cuadro II: Adquisiciones de propiedades rurales

\begin{tabular}{|l|l|r|r|}
\hline AÑO & PROPIEDAD & \multicolumn{1}{|l|}{ PRECIO } & \multicolumn{1}{l|}{ TOTAL* } \\
\hline 1469 & Alcacer & 500 & 500 \\
\hline
\end{tabular}

\footnotetext{
${ }^{34} \mathrm{ACC}$, Capellanías, leg. 54, doc. 17, f.2 v.

${ }^{35} \mathrm{ACC}$, Capellanías, leg. 54, doc. 17, f. 1 r.
} 


\begin{tabular}{|c|c|c|c|}
\hline 1477 & Tierras de pan llevar & 15.000 & 15.000 \\
\hline 1479 & Viña & 3.000 & 3.000 \\
\hline 1479 & $\begin{array}{l}\text { 1/18 dehesa Encín de los Álamos, } 166 \text { mrs } \\
\text { y } 4 \text { cornados }\end{array}$ & 11.015 & 12.020 \\
\hline 1489 & 1/40 parte dehesa de Valvellido & 22.000 & 22.000 \\
\hline 1481 & $\begin{array}{l}\text { 1/18 dehesa Encín de los Álamos, } 166 \\
\text { mrs. y } 4 \text { cornados }\end{array}$ & 20.000 & 20.000 \\
\hline 1481 & 1/12 dehesa del Encín de los Álamos & 25.000 & $25.640,5$ \\
\hline 1481 & $\begin{array}{l}250 \mathrm{mrs} \text { en la majada de la dehesa de Mal- } \\
\text { partida }\end{array}$ & 5.000 & 5.000 \\
\hline 1482 & Tierras de Torrejoncillo, con el fruto & $9.000^{(1)}$ & 7.897 \\
\hline 1486 & Dehesa de Vega de Ruy Díes & $160.000^{(2)}$ & 180.000 \\
\hline 1487 & 1/4 y medio del sexmo dehesa Salgadilla & 19.000 & 19.837 \\
\hline 1488 & Un ochavo en la Vega de Ruy Díes & $50^{(3)}$ & \\
\hline 1488 & 1/80 parte de la dehesa de Valvellido & 11.000 & 11.000 \\
\hline 1489 & $\begin{array}{l}\text { Un ochavo de la Sauceda y media Ysleta } \\
\text { de Rodrigayres }\end{array}$ & 65.000 & 65.000 \\
\hline 1490 & 200 mrs de yerva en la dehesa de Sauceda & 36.000 & 36.900 \\
\hline 1490 & $\begin{array}{l}\text { La mitad del cuarto de la dehesa de la Sau- } \\
\text { ceda, } 2.000 \text { mrs de yerva }\end{array}$ & 26.000 & 26.000 \\
\hline 1491 & La ochava parte de la dehesa de la Sauceda & 45.000 & 46.175 \\
\hline 1492 & Ochavo de tierra & 1.500 & 1.500 \\
\hline
\end{tabular}

* Aparece con el pago de la alcabala

${ }^{1}$ Menos una deuda de $1.103 \mathrm{mrs}$

${ }^{2}$ Además de los $160.000 \mathrm{mrs}$, hay que añadir los $5.500 \mathrm{mrs}$ de renta, 60 fanegas de trigo, un puerco, un cornado y tres pares de gallinas, que hacen un total de $180.000 \mathrm{mrs}$.

$50 \mathrm{mrs}$ en la majada de la dehesa de Malpartida.

La adquisición de las numerosas propiedades rústicas, según consta en el Cuadro II, se encuentra repartida en tres etapas. La primera comienza, tímidamente, con la compra de un alcacer, valorado en $500 \mathrm{mrs}$, en el año 1469. La segunda etapa (1477-1482) se caracteriza por la pequeña adquisición de varias partes de diferentes dehesas, con un valor total de $110.557,5 \mathrm{mrs}$, es decir, un 22,22\% del total invertido. Estas compras, supuestamente, se realizaron con el dinero obtenido de la prebenda del canónigo. Pero, será en 
la tercera etapa (1486-1492), cuando la hacienda del canónigo sufra una importante transformación al formar parte la dehesa la Vega de Ruy Díaz, además de otras dehesas. La inversión realizada durante los últimos ocho años de la vida del canónigo Amusco ascendió a 386.412 mrs, es decir, el 77,68\% del total invertido.

El esfuerzo inversor realizado en esta última etapa corresponde, no sólo al aporte de su prebenda, sino al dinero conseguido con el arrendamiento de las propiedades contenidas en el segundo periodo. Además, hay que destacar que la mayor parte del dinero para la compra de dehesas fue de $469.572,5 \mathrm{mrs}$, es decir, un $94,39 \%$ de la propiedad rústica, mientras que la compra de otras propiedades de menor entidad (un alcacer, una viña, tierras de pan de llevar y un ochavo) supuso el pago de $27.897 \mathrm{mrs}$, es decir, un $5,61 \%$ del total invertido, una cifra muy inferior si la comparamos con la dedicada a las dehesas. Esta enorme diferencia delata la importancia de la dehesa en la economía bajomedieval extremeña ${ }^{36}$ a través de un sistema de aprovechamiento agroganadero de este espacio agrario, donde se desarrolló el ganado mesteño.

\subsection{La propiedad urbana}

La residencia de los miembros del cabildo en la ciudad de Coria era una de las obligaciones más importantes impuestas por las Constituciones y Sínodos llevados a cabo en la Catedral de Coria durante la Edad Media. La residencia era realizada durante un periodo de tiempo determinado y siempre bajo la supervisión y licencia del cabildo. De este modo, la ausencia de algún capitular sin el correspondiente permiso era motivo de sanción. Para llevar a cabo la residencia en la ciudad, el cabildo tenía a su disposición cierto número de casas para acoger a los capitulares. Así, encontramos la referencia a las casas del cabildo donde durante algún tiempo vivió el mayordomo Amusco, quien dijo que a finales del año de 1473 "avía tenido las casas ad vitam refeçionem e agora el non las avian nesçesarias por tener otras" ${ }^{37}$. La compra de una casa propia denota el afán inversor en bienes raíces en detrimento de otras actuaciones encaminadas al arrendamiento. Estas últimas apenas aparecen en el inventario.

La casa de don Hernando Alonso de Amusco, perteneció a Alonso Gutiérrez de la Calleja y a Martín Yánez, cura de Santiago, le costó la cantidad de $93.000 \mathrm{mrs}^{38}$. Este importe de dinero contrasta con la utilizada en la compra de un casar, perteneciente al cura Ferrand Alonso, por 1.000 mrs. Este casar, una vez rehabilitado, fue a manos de los dos capellanes encargados

${ }^{36}$ Julián CLEMENTE RAMOS, La organización del terrazgo agropecuario en Extremadura (siglos $X V-X V I)$, "En la España Medieval", 28 (2005), p. 75.

${ }^{37} \mathrm{ACC}$, Actas Capitulares, leg. 170, doc. 1, f.22 r.

${ }^{38} \mathrm{ACC}$, Capellanías, leg. 54, doc. 14, f.2 r. 
de su capellanía. La remodelación consistió en la realización de dos casillas con chimenea, una para cada uno de ellos ${ }^{39}$.

En enero de 1493, el canónigo Amusco adquiere, mediante un traspaso, las casas que fueron del judío Yuda de Alva pues pagó los 13.000 mrs que le valieron a Rodrigo de Vidana. La adquisición de esta morada estuvo enmarcada en los acontecimientos acaecidos en Castilla tras la aprobación por parte de los Reyes Católicos del Decreto de Expulsión de los judíos y que afectó a un número importante de ellos en la ciudad de Coria ${ }^{40}$.

Fuera de la ciudad de Coria, en 1474, el bachiller Hernando Alonso de Amusco adquirió en el lugar del Acebo unas casas con corrales, establo y vergel por un valor de $12.000 \mathrm{mrs}^{41}$. A esta construcción se suma, en 1481, un vergel propiedad del comendador frey Gutierre de Montalbán (620 mrs). Los reparos realizados para unir ambas propiedades ascendieron a $1.500 \mathrm{mrs}$. La ubicación de esta casa situada en la Sierra de Gata responde a cuestiones relacionadas con la climatología de la zona cauriense. Según se recoge en el Sínodo de 1457-58 Coria era una ciudad "enferma, en especial en los veranos" $" 42$ y que debido a las altas temperaturas los miembros del cabildo vivían durante esos meses en varias localidades de la Sierra de Gata. En este caso, dicha casa corresponde a la residencia de verano del canónigo, con unas condiciones de habitabilidad buenas por las estancias que se encuentran en ella.

Junto a estas propiedades, encontramos en Coria un casar que fue de Juana Díez de Narváez y, que el canónigo Amusco, arrendó a Salomón Paché por $200 \mathrm{mrs}$ anuales. Ésta será la única propiedad urbana arrendada por parte del canónigo. Este hecho pone de manifiesto el interés por invertir en las propiedades urbanas estrictamente necesarias.

\subsection{Las caballerías}

La inversión realizada en caballerías por Hernando Alonso de Amusco consistió en animales de tiro - mulas, mulos y caballos - para la realización de diversas tareas domésticas: acarreo de productos, tareas agrícolas o para la realización de viajes. La importancia de los equinos era pieza fundamental en la economía de la época. El precio por un animal de tiro, tal como podemos comprobar en la tabla, era importante. El desembolso realizado es el siguiente:

\footnotetext{
${ }^{39} \mathrm{ACC}$, Capellanías, leg. 54, doc. 17, f.2 v. Fundación de la capellanía de Amusco: Coria. 1489-03-25.

${ }^{40}$ José Luis Martín Martín y M ${ }^{a}$ Dolores García Oliva, Historia de Extremadura. Los tiempos medievales, Tomo II, Badajoz, 1985, p. 364.

${ }^{41}$ ACCo, Capellanías, leg. 54, doc. 14, f.9 r.

${ }^{42}$ Antonio GarCía Y García (dir.), Synodicon Hispanum. V. Extremadura: Badajoz, CoriaCáceres y Plasencia, Madrid, 1990, p.144.
} 
Cuadro III: Cabaña caballar

\begin{tabular}{|l|l|l|r|r|}
\hline AÑO & CARACTERÍSTICAS & EDAD & \multicolumn{1}{|l|}{ PRECIO } & \multicolumn{1}{|c|}{ TOTAL** } \\
\hline 1488 & acémila pequeña* & 4 años & 2.800 & 2.880 \\
\hline 1490 & mula & 3 años & 8.993 & 8.993 \\
\hline 1491 & macho castaño & 1 año & 4.102 & 2.102 \\
\hline 1491 & acémila parda & 4 años & 6.500 & 4.000 \\
\hline 1491 & mula & 2 años & 6.500 \\
\hline 1493 & caballo alazán & 3 años & acémila* +3.800 & 3.800 \\
\hline
\end{tabular}

** Aparece con el pago de la alcabala.

\subsection{Los esclavos}

La presencia de una minoría social marginada como la de los esclavos en la sociedad bajomedieval extremeña debió ser vista con normalidad y aceptada por ella. El principal factor de la presencia de esclavos en Extremadura fue su proximidad con el reino de Portugal, principal importador de esclavos de Africa hacia el continente europeo ${ }^{43}$. El comercio de esclavos con el reino vecino se llevaba a cabo a través de la amplia frontera con Extremadura $^{44}$. La condición social y jurídica del esclavo estaba por debajo de otros miembros de la sociedad ${ }^{45} \mathrm{y}$, el caso de la mujer es el más relevante. La historia de la mujer en la Edad Media ha estado sometida a su escasa valoración en la sociedad. En la obra del profesor Manuel Fernández Álvarez ${ }^{46}$ podemos resaltar las condiciones sociales de la mujer en el Renacimiento.

La presencia de esclavos en la casa del canónigo Amusco estaba relacionada con el servicio doméstico. De este modo uno de los aspectos más importantes en la vida del canónigo Amusco fue, sin duda, su preocupación por los sectores de la población más desfavorecidos de la época bajomedieval, como fueron los esclavos, aunque la posesión de éstos marcaba el estatus social como símbolo de distinción. El bachiller Amusco, según el inventario,

\footnotetext{
${ }^{43}$ Enric GUINOT RodrígUEZ, La Baja Edad Media en los siglos XIV-XV. Economía y sociedad, Madrid, 2003, pp. 207-273.

${ }^{44} \mathrm{M}^{\mathrm{a}}$ del Rocío PERIÁÑez Gómez, Los esclavos, una minoría marginada en la sociedad extremeña de los Tiempos Modernos, en "XXX Coloquios Históricos de Extremadura", Trujillo, 2001, pp. 443-458.

${ }^{45}$ Alfonso Franco SILVA, La esclavitud en Castilla durante la Baja Edad Media: aproximación metodológica y estado de la cuestión, "Historia. Instituciones. Documentos", 6 (1979), p. 117.

${ }^{46}$ Manuel FERnÁNDEZ Álvarez, Casadas, monjas, rameras y brujas. La olvidada historia de la mujer española en el Renacimiento, Madrid, 2002, pp. 75-77.
} 
adquirió tres esclavos, dos hombres y una mujer, de edades comprendidas entre los 7 y los 16 años. La característica principal es la juventud de estas personas, aunque lo más significativo es la diferenciación que el bachiller realiza sobre los moros o musulmanes y los negros. De esta manera, Geyna y Galante, moros, reciben el sacramento del bautismo, convirtiéndose en cristianos nuevos con sus nuevos nombres: María y Juan, respectivamente. El esclavo negro llamado Sanbita, según los documentos, no recibe el bautismo. También, es notoria la diferencia entre la cantidad de maravedíes pagada por Geyna en relación con los otros dos esclavos varones. La causa de este precio se relaciona con el carácter sumiso de la mujer y la posibilidad de engendrar nuevos esclavos.

\section{Cuadro IV: Esclavos}

\begin{tabular}{|l|l|c|r|r|}
\hline AÑO & NOMBRE & EDAD & \multicolumn{1}{|l|}{ PRECIO } & \multicolumn{1}{|l|}{ TOTAL } \\
\hline 1479 & ${\text { Geyna, } \text { mora }^{47}}^{4}$ & 16 & 9.500 & $10.230^{*}$ \\
\hline 1488 & ${\text { Galante, } \text { moro }^{48}}^{14}$ & 12 & 6.500 & 6.500 \\
\hline 1492 & Sanbita, negro & 7 & 6.000 & 6.000 \\
\hline
\end{tabular}

* Incluye los 330 mrs de la alcabala y otros 400 mrs en concepto de corretaje

La presencia de los esclavos, convertidos en criados, en la morada del canónigo responde a la necesidad de cubrir el servicio doméstico de su casa. De esta manera, encontramos a María López (Geyna), en 1495, como testigo en el proceso abierto sobre la muerte del canónigo Hernando Alonso de Amusco. En las distintas repuestas dadas por la criada, encontramos que ella ha estado al servicio del canónigo durante unos 18 años, periodo contrastado desde su compra hasta la muerte del canónigo y que durante ese tiempo ha acumulado una cantidad de dinero próxima a los $10.000 \mathrm{mrs}$. En la documentación aparece el acemilero del canónigo llamado Aparicio ${ }^{49}$, pero existen escasas referencias a él. Frente a este grupo de miembros marginados, aparece un grupo de personas relacionadas con el canónigo Amusco, se tratan de los criados con características distintas al resto, porque se trata de personas que están en un nivel parecido al parentesco familiar. En este grupo encontramos a Fernando de Montemayor, Juan Nieto y Gonzalo Gil ${ }^{50}$, todos ellos relacionados con la catedral.

\footnotetext{
${ }^{47}$ Rebautizada con el nombre de María.

${ }^{48}$ Rebautizado con el nombre de Juan.

${ }^{49}$ ACCo, Capellanías, leg. 54, doc. 14, f.16 v.

${ }^{50}$ ACCo, Capellanías, leg. 54, doc. 14, ff. 12 v-13 r.
} 


\section{AJUAR DOMÉSTICO Y OBJETOS DE USO DIARIO}

En el desarrollo de la vida cotidiana ${ }^{51}$ de cualquier miembro de la sociedad bajomedieval la casa era el espacio donde se desarrollaba buena parte de la vida de cada individuo. Para conocer los objetos que rodeaban la vida privada del canónigo Hernando Alonso de Amusco, tenemos que volver sobre el inventario de sus bienes. En él podemos encontrar gran número de elementos que conforman el ajuar doméstico y objetos personales. En un primer momento, se caracteriza por un escaso número de elementos que componen la ropa o ajuar doméstico, aunque, el número de elementos de los objetos de uso diario es muy superior. Es notoria la ausencia de referencias a la vestimenta, litúrgica o no, del bachiller. Esta omisión pudiera estar relacionada con la austeridad llevada por el propio bachiller, pues en esta parte del inventario los detalles son meramente descriptivos, aunque en ocasiones, anota el lugar del cual provienen o se encuentran.

En relación con el ajuar doméstico llama la atención el número de colchones anotados por el bachiller quizás por el acaparamiento provocado por la adquisición de las diferentes casas. Junto a estos colchones, las escasas referencias las encontramos relacionadas con la presencia de varias alfombras, tapices o alhamares, almohadas, sargas y paños de camas. Todos estos elementos se relacionan con la ropa blanca dedicada a vestir camas y estancias. Junto a estas ropas, encontramos los muebles relacionados con la guarda de objetos o prendas, como por ejemplo una "asedilla" o galán de noche para limpiar la ropa de vestir o una "balisya" o percha para colgarla, además, de armarios o bancales donde se depositaban las armas.

Los enseres u objetos de uso diario descritos en el inventario se dividen en tres grupos diferenciados entre sí. Para esta clasificación, hemos optado por la distinción de objetos de plata, muebles y otros objetos. Entre los objetos de plata ${ }^{52}$ encontramos un salero, un jarro, dos tazones, un tazón pequeño, una taza dorada, una cazuela, seis plateles, dos "escodellas", seis cucharas, una cinta guarnecida en plata y un sello de plata. A esta lista hay que añadir un pesillo de oro y elementos de escritura con aplicaciones en plata.

En el apartado del mobiliario encontramos ocho arcas de diferentes capacidades, diez mesas de diferentes características, un cofre, dos calderas, una caldereta, un brasero, cuatro candeleros, dos almireces, una llar, una trébede, dos candiles, nueve silletas, dos sartenes, cuatro asaderos tres cucharas y una badileja, dos badiles, dos platos grandes de peltre y uno mediano, cinco camas, dos bancos y una banqueta, dos sacaderos de pozo, varios corchos, dos tinajas para aceite, otras tres para harina, tres tinajas para vino, dos tinajas para agua, cinco cueros y un becerro grande para el vino, y otras tres tinajas para guardar otros productos. Una artesa grande, tres

\footnotetext{
${ }^{51}$ Alfonso Franco Silva, La fortuna y el poder, Cádiz, 1996, p. 390.

${ }^{52} \mathrm{ACC}$, Capellanías, leg. 54, doc. 14, f.3 r.
} 
talleros, una artesa mediana y tres artesas pequeñas, un cajón para pañuelos y joyas, y otro para la custodia de las escrituras, balanzas, dos piedras para amolar, dos candados, aperos de bestias y varios cántaros. Cabe resaltar la importancia del mobiliario relacionado con la conservación de alimentos (aceite, vino y harina) que está relacionada íntimamente con el contexto de una economía agraria, característica de finales del Medievo.

Entre el último grupo, los objetos que más llaman la atención son varios elementos relacionados con el arte de la guerra y la caza, como son dos partes de corazas negras, una espada vieja, dos celadas, una bavera, un barbote, cinco ballestas o dos lanzas entre otros objetos. También encontramos un elemento relacionado con el juego como es un "tablero con tablas para jugar" ${ }^{53}$. La aparición de este juego pone de relieve las actividades de ocio llevadas a cabo por el canónigo Amusco. El juego, a finales de la Edad Media, fue una práctica habitual en la sociedad, ya fuera lícito o no. La Iglesia no escapó a la práctica, prueba de ello es el tablero contabilizado en el inventario del canónigo. La Iglesia, en su afán por controlar la moral y disciplina de los fieles, promovió el control de la moral y comportamiento de los fieles a través de normas contenidas en los sínodos. Aunque, según la profesora $\mathrm{M}^{\mathrm{a}}$ Dolores García Oliva respecto al juego en la diócesis de Coria hubo una permisividad mayor que en el resto de las diócesis extremeñas ${ }^{54}$. Por esta razón, no es extraño encontrar el juego de las tablas en casa de un canónigo tan importante como lo fue Hernando Alonso de Amusco. Como podemos observar, los objetos no son muy numerosos, pero son los precisos para llevar a cabo una vida cómoda, tanto en la ciudad, como en la residencia de verano de Acebo.

\section{LA BIBLIOTECA DEL CANÓNIGO}

En la Catedral de Coria junto a la existencia del Archivo también hubo la Biblioteca ${ }^{55}$ donde se recogieron las obras más importantes que fomentaron la vida intelectual catedralicia durante la Baja Edad Media. Entre los ejemplares más importantes que han llegado a nuestros días destacan la hoja autógrafa de Santo Tomás de Aquino, Floretum ${ }^{56}$ de "El Tostado", la Biblia propiedad de San Pedro de Alcántara (1494), un Graduale (1511), Missale secundum consuetudinem alme ecclesie cauriensis (1530) y un número considerable de libros litúrgicos y cantorales. El desarrollo cultural

\footnotetext{
${ }^{53} \mathrm{ACC}$, Capellanías, leg. 54, doc. 14, f.3 v.

${ }^{54} \mathrm{M}^{\mathrm{a}}$ Dolores GARCÍA OLIVA, De norma y práctica: reglamentación eclesiológica y vida cotidiana en la Extremadura de fines del Medievo, "Norba. Revista de Historia", 16 (1996-2003), p. 379 .

${ }^{55}$ Jesús SAN PEDRO, Restos de una gran biblioteca en la Catedral de Coria, "Alcántara”, 135 (1960), p. 23.

${ }^{56}$ El Floretum es una recopilación y revisión realizada por el obispo Pedro Ximénez de Préxamo sobre la exposición del Evangelio de San Mateo realizada por el polígrafo El Tostado. El libro consta de dos tomos impresos en Sevilla (1491).
} 
en Coria, se debió, en gran parte, a la llegada del obispo don Pedro de Préxamo (1489) y la creación de la primera imprenta en Extremadura ${ }^{57}$. Esta situación se vio beneficiada por la proximidad de la Universidad de Salamanca. En esta institución académica, las carreras de Derecho y Teología fueron las más importantes durante la Baja Edad Media. En los estudios de Derecho los textos más utilizados fueron las Decretales de Graciano, las Clementinas, las Extravagantes y la legislación Justinianea, el Fuero Juzgo y las Siete Partidas. Mientras que en Teología se estudiarán entre otras obras las Sentencias de Pedro Lombardo, Suma Teológica de Santo Tomás de Aquino, la Biblia y autores de las diferentes escuelas europeas ${ }^{58}$.

En este clima de desarrollo intelectual no es extraño que el bachiller Amusco tuviera un interés por el estudio del Derecho y que se viera reflejado en su biblioteca particular. En el cuaderno de las propiedades del canónigo Hernando Alonso de Amusco encontramos una relación de los libros relacionados con sus estudios de Derecho, pues era bachiller en Decretos. En primer lugar, destacamos el gran número de volúmenes recogidos en el inventario y la gran diversidad temática. En dicha relación podemos encontrar diversos libros jurídicos, eclesiásticos o económicos. Las obras contempladas en el inventario se presentan escritas en latín y castellano, principalmente ${ }^{59}$

Entre los libros jurídicos más destacados encontramos varios Decretales, Clementinas, Digesto viejo y otro nuevo, repertorios de Bartolo da Sassoferrato, Juan Miles y Baldo, el Ordo Iudiciaris, varias Partidas, varios volúmenes sobre las leyes de Inocencio $\mathrm{VI}^{60}$ y glosas sobre el Fuero Juzgo y los Ordenamientos de Alcalá. Entre los libros litúrgicos encontramos un Breviario, la Suma de Hostiensis (Tratado de la Eucaristía), Suma de Azo, los Abades, varios tomos del Esforzado (relacionado con la liturgia de las Horas), y varios ejemplares sobre las epístolas. En el apartado de libros relacionados con la economía hallamos obras relacionadas con las leyes relacionadas con alcabalas y las monedas, además de un manual sobre aritmética.

La presencia de estos libros en la biblioteca particular del bachiller Hernando Alonso de Amusco refleja una formación académica completa para acceder a los diferentes cargos importantes dentro del cabildo y su formación fue el aval para que fuese considerado como un miembro destacable del cabildo.

\footnotetext{
${ }^{57}$ Hipólito EscOLAR, Historia del libro, Madrid, 1988, p. 343; Antonio RoDrÍGUEZ-MOÑINO, La imprenta en Extremadura (1489-1800), Badajoz, 1945, p. 12; Antonio ODRIOZOLA, La imprenta en Castilla en el siglo XV, en Historia de la imprenta hispana, Madrid, 1982, pp. 144145; Belén DíAZ MELlADO, Catálogo de impresos del Fondo Antiguo de la Catedral de Coria, Salamanca, 1995, pp. 9-10 (Memoria de Diplomatura).

${ }^{58}$ Francisco MARTÍN FERNÁNDEZ, Enseñanza y universidades españolas del siglo XI al XIV, en Historia de la Iglesia: El Pensamiento medieval, vol. XIV, Valencia, 1974, p. 653.

${ }^{59}$ José Manuel NIETO SORIA, Iglesia y génesis del Estado Moderno en Castilla (1369-1480), Madrid, 1994, pp. 189-222.

${ }^{60}$ Juan María LABOA GALLEGO, Historia de los Papas. Entre el reino de Dios y las pasiones terrenales, Madrid, 2005, p. 248. Las leyes promulgadas por Inocencio VI (1352-1362), conocidas como las Constituciones Egidianas, permanecieron con escasas modificaciones hasta 1816.
} 
Junto a la biblioteca, destacan los instrumentos de escritorio que el canónigo Hernando Alonso de Amusco anotó en el inventario. La lista de los objetos enumerados recoge varios canivetes, tijeras, escribanías, cuadrante, tinteros o un pesillo de oro con su caja. Entre estos objetos encontramos un "sello de plata de una caldera" ${ }^{61}$ relacionado con la familia de Lara de Manrique que serviría para el sellado de los documentos redactados por el canónigo. En una nota aparecida en las actas capitulares, aparece una deuda del canónigo Amusco, en su etapa de mayordomo del cabildo, en relación con unas telas y brocados encargados en la feria de Medina del Campo. El 4 de junio de 1495 la deuda se salda con la tasación de los "veynte y tres libros de los que quedaron del dicho bachiller Fernand Alonso de Hamusco. En los quales dichos libros se montaron diez e syete mill e sesenta e çinco mrs. Los quales dio para en parte de pago de la debda quel dicho bachiller e el dicho Montemayor en su nonbre, como su heredero, deven a la dicha yglesia del cargo de mayordomía que tovo el dicho bachiller de la dicha yglesia" ${ }^{2}$.

\section{CONCLUSIONES}

La vida y carrera eclesiástica del bachiller en Decretos Hernando Alonso de Amusco, canónigo de la Catedral de Coria se vio favorecida, por el obispo de Coria, don Iñigo Manrique de Lara, su tío. La concesión por parte de la canonjía supuso un avance en la economía del canónigo. El proceso de enriquecimiento económico fue lento, aunque la mayor parte de sus inversiones se realizaron en los tres últimos lustros de su vida. La elevada cuantía de maravedíes invertidos en propiedades rústicas pone de manifiesto el nivel económico que acumuló nuestro personaje. La compra de casas, dehesas y otras heredades fueron sus ejes de inversión más importantes.

La extremada precisión en las anotaciones del inventario denota el carácter juicioso llevado a cabo en sus actividades capitulares. Aunque el ajuar doméstico no es muy extenso, la relación de las obras de la biblioteca demuestra, por un lado, su bagaje académico y, por otro, el trabajo realizado dentro de la institución eclesiástica del obispado de Coria, además de ciertos aspectos de la vida cotidiana del canónigo.

Como punto final, la importancia del estudio de este personaje radica en la necesidad de obtener información veraz que nos ayude a estudiar una escala social eclesiástica, como es la de los canónigos, a través de sus inventarios de bienes.

Fecha de recepción del artículo: noviembre 2006.

Fecha de aceptación y versión final: noviembre 2007.

\footnotetext{
${ }^{61} \mathrm{ACC}$, Capellanías, leg., 54, doc. 14, f.3 r.

${ }^{62} \mathrm{ACC}$, Actas Capitulares, leg. 170, doc. 3, f.51 v.
} 